\title{
Understanding Bourdieu - Cultural Capital and Habitus
}

\author{
Xiaowei Huang \\ Correspondence: Xiaowei Huang, School of Art \& Design, Guangzhou College of Commerce, Guangzhou, Guangdong
}

Received: July 6, 2019 Accepted: July 23, 2019 Online Published: August 7, 2019

doi:10.5539/res.v11n3p45 URL: https://doi.org/10.5539/res.v11n3p45

\begin{abstract}
This research paper aims at providing a brief and exemplified introduction of the French sociologist Pierre Bourdieu's two particularly important theoretical concepts: Cultural Capital and Habitus. Cultural capital, according to Bourdieu, is gained mainly through an individual's initial learning, and is unconsciously influenced by the surroundings (Bourdieu, 2000). In the case of habitus, it relates to the resource of knowledge (Bourdieu 1990). Knowledge is about the way how people view and understand the world, which is gained via a specific culture that an individual lives in. While also showing how Bourdieu's work on economic capital, social capital and cultural capital can help us to understand the contemporary world and its practices.
\end{abstract}

Keywords: economic capital, social capital, cultural capital, cultural field, habitus

\section{Introduction}

Pierre Bourdieu has given rise to three particularly important theoretical concepts: cultural capital, cultural field, and habitus. He categories capital into four forms: economic capital, social capital, cultural capital and symbolic capital. This paper focuses on the first three forms of cultural capital. Economic capital refers to possessing economic resources, such as money and properties. These are constructed by elements of production. These elements can be land, factories, jobs, inherited income and possessions, such as buildings, pictures, and ceramics. The meaning of social capital can be understood as the contacts, social networking and relationships an individual can be part of or operate. For example, people from China frequently use the term 'Guanxi' to describe the relationship they have with friends they know directly or indirectly in different fields. Specifically, one talks about 'Guanxi' in terms of those who have power in that field, such as the principal of a college or the leader of a government department. A relationship of 'Guanxi' means a problem or difficult situation can be solved more easily and conveniently, by way of appealing to the relevant contact. Social capital can also be explained by way of this example. Cultural capital is slightly different. Webb, Schirato and Danaher define it as:

A form of value associated with culturally authorized tastes, consumption patterns, attributes, skills and awards. Within the field of education, for example, an academic degree constitutes cultural capital (Webb, Schirato \& Danaher, 2002, p. x).

\section{The Relationship Between Economic Capital, Social Capital and Cultural Capital}

The relationship between these economic capital, social capital and cultural capital is transformational but non-replaceable. By way of example, an individual who has some valuable social networks, such as knowing important or influential people, can be said to have social capital; moreover, this can be transferred to economic capital. In China, it is quite difficult to see a medical doctor due to the limited quota that each doctor holds, and the large number of patients who register every day. There is always a long queue lining up in the early morning before the opening hour of a hospital. Making a phone call to consult your friend the doctor for some health problems, instead of going to the hospital in person, can save lots of time if the situation is not that serious. In this way, social capital can be seen as transferable to economic capital. However, the relationship between social capital and economic capital is neither stable nor straightforward (Bourdieu, 2005). Knowing a friend who is a doctor can be understood as a sort of social relationship, it does not stand for any material object, such as money and properties.

A person who grows up in a wealthy family could be more easily offered an opportunity to study abroad and gain some valuable qualifications and experience. This advantage can be seen as a form of cultural capital. That could lead to the person being offered a position in a company. This situation explains how cultural capital is transferable to economic capital. With this position, a person is able to expand social networks and build up more friendships, which is understood as social capital. This example demonstrates the transformational relationship of economic, social, and cultural capital. However, these three forms of capital are non-replaceable; in other words, they exist with their own independent logic and 
contexts. The value of cultural capital, for instance, can only exist in certain particular situations, and cannot be replaced directly by either economic capital or social capital (Bourdieu, 1993).

By way of example, a doctor of Chinese medicine (DCM) is highly respected in China, since Chinese medicine is a discipline that requires time-consuming study and the accumulation of experience. Before becoming a Chinese medicine doctor, one must go through a long process of learning: first of all, one has to spend many years studying each kind of herbs in terms of its characteristics and functions. Secondly, the student needs to know how to mix up different kinds of herbs in order to produce best results in treatment, or else his career will be damaged if there is a simple mistake. Finally, gaining experience is another matter of time. In order to get and accumulate experience, a medical student has to spend a long period of time accompanying the supervisor as the supervisor consults with patients.

A DCM's cultural capital derives from his qualifications and his knowledge, particularly his knowledge of the Chinese context and cultural field. Cultural capital, in this case, can be transferred to economic capital. However, a DCM's cultural capital might not be transformed quite so easily into economic capital outside of China. For example, an American patient might choose not to consult a DCM in the U.S. A DCM might not achieve the same level of success outside China due to the different forms of knowledge being privileged, such as knowledge of herbal medicines. A DCM, whose qualifications represent cultural capital in China, cannot connect them to the same level of economic capital outside China.

Returning to the concept of cultural capital, in the initial process of growing up, parents are considered as the first teachers of their children. In a similar way, families are seen as the institution that offers education. Education in this specific sense can refer to the training of behavior and etiquette: a young person is taught to be polite while having a conversation with elders, for instance. This kind of education is not the same as the specialized or professional knowledge gained from school or university. Bourdieu argues that family plays an important role for an individual in acquiring cultural capital (Bourdieu \& Wacquant, 1992). For example, a wealthy family can support their children and enable them to study abroad or get into an exclusive school in order to grasp knowledge and prestigious qualifications. According to Bourdieu, cultural capital exists in three forms - embodied state, objectified state, and institutionalized state (Bourdieu 1986).

The embodied state is understood as comprising of elements such as skills, the habitus, styles of conversation and posture. In other words, it is about knowledge and culture as it is communicated through a person's mind hexis (Bourdieu, 1990). According to Schirato, Danaher and Webb, bodily hexis refers to "the forms of bodies, and bodily movements and deportment that are commensurate with, authorized by and appropriately reflected the values of cultural field" (Schirato et al., 2012, p. xviii). These are provided by the family and school. The objectified state is about material objects - books, paintings and ceramics, for instance. These goods are cultural products that are associated with cultural capital; and an individual can acquire cultural capital through possessing them. The institutionalized state of cultural capital can be understood as a recognized certificate or license. The institutionalized state in this sense is comparable and exchangeable. By way of example, a certificate from the United Kingdom can be compared with one from the United States in terms of education quality and status. Moreover, a Chinese person who holds a certificate from a well-known university in the United Kingdom might get a higher salary in China compared with those who hold a local degree from China. In certain areas, such as with a certified medical doctor, the license he/she holds can be regarded as a guarantee of economic capital. The institutionalized state of cultural capital makes possible to transform from cultural capital to economic capital.

\section{Defining Cultural Field}

Bourdieu uses the term 'cultural field' to explain the dynamics of capital. He claims that choice making is a reflection of one's taste. Taste can be mapped on a person's social status (Bourdieu, 1989). Food preference, for instance, can be seen as a way to distinguish a person's background. A person from the upper class might prefer to choose food that has nutritional ingredients; or they might prefer to consume prestigious brands (of wine or cheese, say). On the other hand, a person from the lower class might focus on the quantity of the food; in other words, satisfying hunger is the most important factor. Moreover, taste makes a distinction and establishes a distance between the higher and the lower class groups. Bourdieu suggests that taste is cultivated from a person's early years. It directs the person to seek an appropriate social status, which is equal to their well-educated background, to guide them to behave elegantly and to distinguish themselves from the others (Baroque).

To sum up, family education can be counted as one of the ways showing people from different class groups have different understandings of the world, since the development of 'taste' depends to a large extent on family background. Cultural capital, in this sense, is gained mainly through an individual's initial learning, and is unconsciously influenced by the surroundings (Bourdieu, 2000). Higher class families and schools provide a different kind of education to the next generation than lower class families. An individual who is trained by a more prestigious school, for instance, will acquire a taste that reflects the values of the school. We can say that taste is not determined by self-development or by spending time trying to improve one's taste, but it is derived from or informed by one's cultural trajectory, most particularly in terms of family and education (Bourdieu, 1989). 
The preferences of diet, culture, and artistic performance, for instance, are reflections of a person's cultural trajectory and social status. Bourdieu claims that the appreciation of art and the capability of playing a musical instrument are not only linked to long-term preferences, but also to economic means, and, more importantly, the leisure of money and power holders (Baroque, 2016). For example, taking a Monet painting and a Beethoven symphony, a higher class group might know how to appreciate these art works since they should more or less have some relevant knowledge. Webb, Schirato and Danaher explain that:

Bourdieu shows that the ability to appreciate art, and possession of a taste for art, are closely connected to one's education and 'class' status. Middle-class people in these studies were far more confident than working-class people about approaching cultural products and cultural institutions. Bourdieu's argument was that this was because they had acquired conceptual skills and social confidence from their families and their middle-class schools, rather than because they were born mysteriously possessed of a 'natural' love of art (Webb et al., 2002, p. 153).

People from the lower classes may not be offered chances to know art and music due to their economic condition. Music classes, for instance, are extremely expensive. Lower class parents might need to work very hard in order to cover the basic expenses of the family. For this reason, their children may have no idea what 'leisure' means to them. Even if they do have some spare time, they might prefer to rest. In their life picture, there is only work and less time for leisure. For lower class, survival is often the priority.

Webb et al. suggest, however, that a lower class migrant family might spend their resources to educate the next generation. For Bourdieu this action is seen as a kind of 'gambling', which is likely to be unsuccessful (Bourdieu, 1998). As Webb et al. write:

Although a lower class migrant family may strive to get its children educated, the habitus of the children will, in advance, disqualify them from success, both in the sense that the children will signal, in everything they do and say, their unsuitability for higher education, and as a corollary, the children will themselves recognize this, and more or less expect failure (Webb et al., 2002, p.24).

Many contemporary Chinese families also 'gamble' on education. Many Chinese nouveau rich realize the importance of education. After becoming rich, their children are sent to study overseas. However, a person's taste, behavior and cultural literacy and tastes cannot be changed easily or quickly.

In China, one can often distinguish a student's family background and social status from the programmes that they select in the college. A large proportion of students who come from wealthy families prefer to major in arts, such as music, performance, and visual art. As well as school fees, students are expected to afford additional and expensive devices, such as a piano or a personal computer with high speed for graphic display. All these devices require financial support. On the other hand, students who come from working-class families tend to major in science and engineering. Without additional but compulsory and expensive equipment, these programmes offer skill-based courses and are more likely to lead to employment.

Apart from the appreciation of art, education and college programmes, people are classified into groups according to their common cultural trajectories. This is to say, individuals build friendships mainly with those who come from similar backgrounds, with similar educational, social and economic status. For example, a woman who is born in a wealthy and well-educated family may have a different perspective from a lower class woman in consuming a product, specifically in terms of its value and function. To her, a fashionable and attractive appearance is absolutely necessary for a handbag; however, those who come from a lower class may consider the functionality of a handbag to be more important. A friendship between a higher class person with a lower class person will be unlikely due to the extremely different backgrounds that they come from. The above examples are similar with Cole's understanding of Bourdieu that:

Cultural capital is the accumulation and knowledge, behaviors, and skills that one can tap into demonstrate one's cultural competence, and thus one's social status or standing in society. ... this accumulation was used to reinforce class differences, as historically and very much still today, different groups of people have access to different sources and forms of knowledge, depending on other variables like race, class, gender, sexuality, ethnicity, nationality, religion, and even age (2019).

\section{The Concept of Habitus}

The above example about friendships between people from two different classes is also applicable to marriage. A perfect match means that the two families-in-law should share a similar social status, income, and family background. A relationship, especially for a couple, may not be stable or happy if there is a big gap between the husband and wife in terms of educational background and life experiences. Their world views will be quite different. This is tied in to Bourdieu's concept of the 'habitus'. According to Webb, Schirato and Danaher, 'knowledge (the way we understand the 
world, our beliefs and values) is always constructed through the habitus, rather than being passively recorded (Webb et al., 2002, p.38).

Bourdieu's concept of the 'habitus' plays a central role in his theories. Webb, Schirato and Danaher define the habitus as:

A concept that expresses, on the one hand, the way in which individuals 'become themselves' develop attitudes and dispositions - and, on the other hand, the ways in which those individuals engage in practices. An artistic habitus, for example, disposes the individual artist to certain activities and perspectives that express the culturally and historically constituted values of the artistic field. (Webb et al., 2002, p. xii - xiii)

Bourdieu's concept of habitus also relates to the resource of knowledge (Bourdieu 1990). Knowledge is gained from a specific culture that an individual lives in. By way of example, a working class person will have a particular, class-based understandings of the world; this will be different to the world view of people from the middle class. Moreover, these understandings are reflected in the person's behavior, such as the ways in which they talk, the usage of vocabulary, and attitudes and values. Bourdieu's concept of 'habitus' can partly be used to explain this situation. According to Bourdieu,

The division into classes performed by sociology leads to the common root of the classifiable practices which agents produce and of the classificatory judgments they make of other agents' practices and their own. The habitus is both the generative principle of objectively classifiable judgments and the system of classification (principium divisions) of these practices. (Bourdieu, 2010, p. $165-166)$

Habitus can be understood as a series of dispositions, which influences a person's expectations of social life. Compared to the working class, a middle class person might be more comfortable in a conversation with professionals, such as lawyers and professors. The main reason for this is the similar background they come from, which leads to similar values, experiences of life and education (Bao, 1997, p.217). By way of example, the level of interaction between faculty in a college is also based on one's family background and personal values. Even though every faculty will have similar or same level of educational background, which is the criterion and standard on requirement for the position, one's values are determined mainly by the family background, which is also linked to Bourdieu's concept of cultural capital.

Obtaining the same educational level does not mean that one's cultural capital would be similar with another's. For example, a PhD holder who comes from a poor family, his understandings of the world and value could be much different from someone who is also a $\mathrm{PhD}$ holder but raised in a rich family. The history of a family plays a crucial role that has powerful impact on one's behaviour as well as habitus. Those who come from a poor family may suffer inferiority complex, which is embodied in the way they interact with others, by not looking in the eyes while talking, for instance. That is to say, educational background does not help too much to build one's cultural capital but the history of family does. This could be referred to what Bourdieu calls: a system. 'the more the competences measured are recognized by the school system, and the more 'academic' the techniques used to measure them, the stronger the relation is between performance and educational qualification' (2010, p. 5). As Bourdieu puts it:

As a system of practice-generating schemes which expresses systematically the necessity and freedom inherent in its class condition and the difference constituting that position, the habitus apprehends differences between conditions, which it grasps in the form of differences between classified, classifying practices (products of other habitus), in accordance with principles of differentiation which, being themselves the product of these differences, are objectively attuned to them and therefore tend to perceive them as natural. (Bourdieu, 2010, p. 167)

An individual's disposition is reflected in actions and behavior unconsciously: they are all invisible, but also marked in and through a person's bodily hexis and socio-cultural behaviour. The habitus for Bourdieu is usually very ingrained, and is capable of maintaining itself over a long period of time. It is, in Bourdieu's words a 'durably installed generative principle of regulated improvisations' (Bourdieu, 1978, p. 78) that determines how a subject sees and experiences the world, what they think and do, and their aspirations, values and practices. It can be understood, more generally, as 'the values and dispositions gained from our cultural history that generally stay with us across contexts ... they are durable and transposable' (Webb et al., 2002, p. 36). The habitus is incorporated, for Bourdieu, at the level of an unconscious set of bodily movements, dispositions and styles. According to Webb et al. as subjects:

Move through and across different fields, they tend to incorporate into their habitus the values and imperatives of those fields. And this is most clearly demonstrated in the relationship between field and habitus functions to 'produce' ... bodies and bodily dispositions (Webb et al., 2002, p. 37).

However, while it is durable and relatively continuous, the habitus can incorporate changes within and across different contexts and conditions (Schirato \& Roberts, 2018). A person's behavior and practices reflect his/her cultural history, 
and that history is always open to change and development. The relationship between these two concepts is interrelation rather than individual existence. Bourdieu points out that:

Systematicity is found in the opus operatum because it is in the modus operandi. It is found in all the properties - and property - with which individuals and groups surround themselves, houses, furniture, paintings, books cars, spirits, cigarettes, perfume, clothes, and in the practices in which they manifest their distinction, sports, games, entertainments, only because it is in the synthetic unity of the habitus, the unifying, generative principle of all practices. (Bourdieu, 2010, p. 169)

\section{Conclusion}

To sum up, Bourdieu's concepts of cultural capital and habitus help us better understand an individual's behaviour and performance. Even though one's personal history is not easy to trace, or we may ask whether or not that is necessary, it is the job of communication scholars to make interpersonal communication more interesting and smooth.

\section{References}

Bao, Y. M. (1997). Cultural capital and social alchemy. (Y. M. Bao, Trans.). Shanghai: Shanghai ren min chu ban she.

Baroque (n.d.). Retrieved from http://nakenote.blogspot.com/p/pierre-bourdieu.html

Bourdieu, P. (1978). Outline of a theory of practice. (R. Nice, Trans.). Cambridge: Cambridge University Press. https://doi.org/10.1017/CBO9780511812507

Bourdieu, P. (1986). The Forms of Capital. Retrieved from https://www.marxists.org/reference/subject/philosophy/works/fr/bourdieu-forms-capital.htm

Bourdieu, P. (1989). Distinction. (R. Nice, Trans.). London: Routledge.

Bourdieu, P. (1990a). In other words. (Various Trans.). Cambridge: Polity Press.

Bourdieu, P. (1993b). The field of cultural production. (Various Trans.). Cambridge: Polity Press.

Bourdieu, P. (2000). Pascalian meditations. (R. Nice, Trans.). Cambridge: Polity Press.

Bourdieu, P. (2005b). The social structures of the economy. (C. Turner, Trans.). Cambridge: Polity Press.

Bourdieu, P., \& Wacquant, L. (1992). An invitation to reflexive sociology. (Various Trans.). Chicago: University of Chicago Press.

Cole, N. (2019). What is cultural capital? Do I have it? Retrieved from https://www.thoughtco.com/what-is-cultural-capital-do-i-have-it-3026374

Schirato, T., \& Roberts, M. (2018). Bourdieu: a critical introduction. Sydney: Allen \& Unwin.

Schirato, T., Danaher, G., \& Webb, J. (2012). Understanding Foucault. Sydney: Allen \& Unwin.

Webb, J., Schirato, T., \& Danaher, G. (2002). Understanding Bourdieu. Australia: Allen \& Unwin.

\section{Copyrights}

Copyright for this article is retained by the author(s), with first publication rights granted to the journal.

This is an open-access article distributed under the terms and conditions of the Creative Commons Attribution license (http://creativecommons.org/licenses/by/4.0/). 